\title{
Serial Position Functions in General Knowledge
}

\author{
Matthew R. Kelley \\ Lake Forest College \\ Ian Neath \\ Memorial University of Newfoundland \\ and \\ Aimée M. Surprenant \\ Memorial University of Newfoundland
}

Address correspondence to:

Matthew Kelley

Department of Psychology

Lake Forest College

Lake Forest, IL 60035

email: kelley@lakeforest.edu

phone: (847) 735-5262
Kelley, M. R., Neath, I. \& Surprenant, A. M. (2015).

Serial position functions in general knowledge. Journal of Experimental Psychology: Learning, Memory, and Cognition, 41, 1715-1727. doi:10.1037/xlm0000141

This article may not exactly replicate the final version published in the APA journal. It is not the copy of record. 


\begin{abstract}
Serial position functions with marked primacy and recency effects are ubiquitous in episodic memory tasks. The demonstrations reported here explored whether bow-shaped serial position functions would be observed when people ordered exemplars from various categories along a specified dimension. The categories and dimensions were: actors and age; animals and weight; basketball players and height; countries and area; and planets and diameter. In all cases, a serial position function was observed: People were more accurate to order the youngest and oldest actors, the lightest and heaviest animals, the shortest and tallest basketball players, the smallest and largest countries, and the smallest and largest planets, relative to intermediate items. The results support an explanation of serial position functions based on relative distinctiveness which predicts that serial position functions will be observed whenever a set of items can be sensibly ordered along a particular dimension. The serial position function arises because the first and last items enjoy a benefit of having no competitors on one side and therefore have enhanced distinctiveness relative to mid-dimension items, which suffer by having many competitors on both sides.
\end{abstract}




\section{Serial Position Functions in General Knowledge}

When people recall a list of items, they frequently recall the first few items well (the primacy effect), the last few items well (the recency effect), but recall the mid-list items quite poorly. One explanation for this ubiquitous U-shaped serial position function is that it arises due to differential contributions from multiple memory systems (e.g., Atkinson \& Shiffrin, 1968; Glanzer, 1972; Davelaar, Goshen-Gottstein, Ashkenazi, Haarmann, \& Usher, 2005; Waugh \& Norman, 1965). The general prediction from these accounts is that primacy and recency effects obtain when the tasks tap a specific combination of episodic memory systems. A different explanation emphasizes the idea that when items are arranged on a dimension such as position, items at the first and last positions will be more distinct than items in middle positions (Brown, Neath, \& Chater, 2007; Neath \& Brown, 2006). The general prediction from this type of account is that primacy and recency effects will be observed whenever people are asked to recall a set of items that can be sensibly ordered along some dimension (Neath \& Saint-Aubin, 2011). The purpose of the experiments reported here is to test the prediction that serial position functions with attendant primacy and recency effects will be observed when the memory test taps general knowledge.

Serial Position Functions and Memory Systems

In the 1960 s and early 1970 s, the dominant account of memory -- the modal model -explained the ubiquitous U-shaped serial position function as reflecting both short- and longterm episodic memory (e.g., Atkinson \& Shiffrin, 1968; Glanzer, 1972; Waugh \& Norman, 1965). The recency effect, better recall of end-of-list items, was due to subjects "dumping" the contents of short-term memory at the start of the recall period. The primacy effect, better recall 
of early list items, was because subjects next retrieved items that had been sufficiently rehearsed that they had been transferred to long-term memory. Mid-list items were recalled worst because they suffered from two problems: Unlike primacy items, they had less chance of being sufficiently rehearsed that they could be transferred to long-term memory. But, unlike recency items, they were unlikely to be in short-term memory at the time of test because too many list items had been presented after them. Evidence supporting this account included the finding that delaying recall, and presumably therefore clearing the contents of short-term memory, selectively removed the recency effect but left the primacy effect intact (Glanzer \& Cuntiz, 1966; Postman \& Phillips, 1965).

This account ran into problems with the publication of results like those reported Bjork and Whitten (1974), who used a continual distractor paradigm. In this task, the same $30 \mathrm{~s}$ of distractor activity that was used to delay recall by Glanzer and Cunitz (1966) occurred after every item in the list, including the final item. The surprising result was that the recency effect re-emerged. Subsequent research has found primacy and recency effects in lists that are as short as a few hundred milliseconds (Neath \& Brown, 2006) to those lasting weeks (Glenberg, Bradley, Kraus, \& Renzaglia, 1983) and even years (Sehulster, 1989). Moreover, when studies directly compared the effects of manipulations on short-term recency (i.e., immediate free recall) and long-term recency (i.e., delayed and continual distractor recall), no differences were found. For example, Greene (1986) showed that word frequency and list length have the same effect on recency whether the test is an immediate free recall or continual distractor test.

Primacy and Recency in Semantic Memory 
Another line of evidence against the multi-store episodic memory account of the serial position function comes from studies in which the test is designed to tap semantic rather than episodic memory. One key difference between these two memory systems is that episodic memory enables the rememberer to be aware of the learning episode whereas semantic memory contains no information about the learning episode (Tulving, 1972, 1983). As Tulving (1985, p. 387) described it, "episodic memory affords the additional capability of acquisition and retention of knowledge about personally experienced events and their temporal relations in subjective time and the ability to mentally 'travel back' in time." Both short- and long-term memory are part of the episodic memory system and are not involved in tests of semantic memory.

However, there are a growing number of studies that show serial position functions when people recall information that is presumably in semantic memory. These effects have been demonstrated when recalling political figures (e.g., Crowder, 1993; Healy, Havas, \& Parker, 2000; Healy \& Parker, 2001; Neath \& Saint-Aubin, 2011; Roediger \& Crowder, 1976; Roediger \& DeSoto, 2014); song lyrics (Kelley, Neath, \& Surprenant, 2013; Maylor, 2002; Overstreet \& Healy, 2011); movies (Kelley et al., 2013, 2014); and the order of the Harry Potter books (Kelley et al., 2013, 2014).

The existence of such data calls into question any account of serial position functions that requires a contribution from both short- and long-term episodic memory. A proponent of the multi-store episodic memory account might question the extent to which the above demonstrations really do show "real" serial position functions. For example, when only the presidential data of Roediger and Crowder (1976; Crowder, 1993) existed, such a proponent could object to the use of presidents as the stimuli and present quite a solid argument that episodic memory was involved. For example, Washington and Jefferson are undoubtedly the 
focus of more classroom time in grade school than Franklin Pierce or Chester Arthur, which is a plausible interpretation of why the Washington and Jefferson are better recalled than Pierce and Arthur. An appeal to a particular president's historical importance is intuitively appealing.

However, as the additional demonstrations were published, such piecemeal explanations quickly became less tenable. The explanation for why presidential and prime ministerial serial position functions are not "real" serial position functions does not apply when song lyrics are used. A separate explanation for the song lyrics - that they somehow conveyed order information - does not work because performance is at chance for those subjects who indicate they did not know the song (see Kelley et al., 2013). Even if that explanation were not contradicted by the data, it would not apply to serial position functions observed when recalling the order in which movies were released or Harry Potter books published. Finally, if one were to argue that the latter demonstrations reflected episodic memory, the data from a remember/know analysis revealed serial position functions when only "know" responses are examined (see Kelley et al., 2014).

In this paper, we provide evidence of serial position functions with a new class of stimuli that are less susceptible to the claim that the information is in episodic memory. We asked undergraduates to order lists of exemplars from a number of different categories based on various characteristics (e.g., age, size, area, etc.). The logic is as follows. Neath and Saint-Aubin (2011) noted that the distinctiveness account of serial position functions makes the following prediction: If a set of items can be reasonably ordered along a given dimension, the first and last few items will be more distinct than middle items simply by virtue of the fact that they have fewer neighbors on one side. In contrast, an otherwise comparable set of items that cannot be reasonably ordered should show no such primacy and recency effects. For example, there is no 
obvious way of ordering the names of the seven dwarves, and there is correspondingly no serial position function observed when they are recalled (Meyer \& Hilterbrand, 1984). But there are a number of ways of sensibly ordering animals. For example, one could ask subjects to list them from dark to light (e.g., from black panther to polar bear) or from tall to short (e.g., from giraffe to mouse) or from fast to slow (e.g., from cheetah to sloth), etc. While it may be plausible to argue that people might remember episodic details from, for example, when they first read the second Harry Potter book (the results of the remember/know analysis notwithstanding), we argue that it is not plausible to say that people might remember the details from when they first learned that a chimpanzee weighs less than a seal.

\section{Serial Position Functions and Distinctiveness}

The relative distinctiveness principle (Surprenant \& Neath, 2009) has been instantiated in a simulation model of memory known as SIMPLE: Scale Invariant Memory, Perception, and Learning (Brown et al. 2007; Neath \& Brown, 2006). This model was originally developed to explain serial position functions in standard episodic memory tasks, such as free recall of a list of words that was just seen, but it has also been fit to the presidential (Neath, 2010) and prime ministerial (Neath \& Saint-Aubin, 2011) serial position functions, as well as those observed when the stimuli were lyrics, books, and movies (Kelley et al., 2013). It has also been fit to such functions that arouse when the stimuli varied along perceptual dimensions such as frequency (i.e., Hz) and length (Neath, Brown, McCormack, Chater, \& Freeman, 2006). For the purposes of the current paper, the model is outlined only briefly; interested readers are referred to the aforementioned papers for complete details including its relation to other models. In this paper, the predictions of the model will be used solely as way of evaluating whether the shape of the 
functions observed resemble those seen in other paradigms. Therefore, we focus only on aspects of the model that are relevant to the current work.

SIMPLE represents items as points along a dimension (or points in multi-dimensional space) where the dimension depends on the task. In the typical episodic task, relative time is frequently the dimension but in other settings, the dimension may be serial position (see Surprenant, Neath, \& Brown, 2006) or some perceptual dimension (Neath, Brown, McCormack, Chater, \& Freeman, 2006). The values on this dimension are log transformed (see Brown et al., 2007, for a detailed discussion) and performance depends on the relative distinctiveness of these log-transformed values.

An item will be remembered to the extent that it is more distinct than close neighbors on the relevant dimension at the time of test. The similarity between two memory representations $i$ and $j, \eta_{i, j}$, with values $M_{i}$ and $M_{j}$ on a psychological dimension, is given by Equation 1:

$$
\eta_{i, j}=e^{-c\left|M_{i}-M_{j}\right|}
$$

As in many models, it is assumed that similarity falls off as a decreasing function of the distance between two representations (e.g., Shepard, 1987). The main free parameter in SIMPLE is $c$ : With higher values of $c$, distant items become less similar and thus have less influence.

The probability of producing the response associated with item $i, R_{i}$, when given the cue for stimulus $j, C_{j}$, is given by Equation 2, in which $n$ is the number of items in the set:

$$
P\left(R_{i} \mid C_{j}\right)=\frac{\eta_{i, j}}{\sum_{k=1}^{n} \eta_{j, k}}
$$


For a reconstruction of order task, as used in the present work, omissions are not possible. Therefore, there is only one free parameter, $c$, and all that need be done to generate predictions is use the values from the dimension to generate recall probabilities.

Note that SIMPLE predicts not only the proportion of correct responses but also the pattern of errors. Indeed, it is the latter prediction that is of most interest in the current work. It is expected that this version of SIMPLE will not produce good quantitative fits, if only because there is a single free parameter in the model and the situation being assessed is complex (retrieval of information from general knowledge). However, the qualitative predictions of SIMPLE are of critical importance: SIMPLE predicts that in all 5 demonstrations, the pattern of errors should be similar to those seen in both short- and long-term episodic tasks (e.g., Healy, 1974; Nairne, 1992). Those predictions will be discussed in more detail below.

The present demonstrations explored whether U-shaped serial position functions are observed when people order exemplars from various categories along a given dimension. The categories and dimensions were: actors and age; animals and weight; basketball players and height; countries and area; and planets and diameter. Subjects were first asked to rate their level of knowledge for each item on a scale from $1=$ not at all knowledgeable to $5=$ extremely knowledgeable. Following the rating task, they were given five separate free reconstruction of order tasks, one for each set of stimuli. The stimuli were shown in a random order on one side of a sheet of paper and subjects were asked to place them into the appropriate order. The data were collected at the same time from the same subjects for all five sets of stimuli, and therefore the methodology is described together, but the data for each demonstration are reported separately.

\section{General Method}




\section{Subjects}

Two hundred and sixty one undergraduate students from Lake Forest College participated for credit in various introductory courses. Subjects completed the study in groups of approximately 40 students in a classroom setting. Each session lasted approximately 15 minutes. Design \& Materials

Five sets of stimuli were assembled: three with roughly even increments between the exemplars and two with uneven increments (see Appendix for details). Seven female actors were chosen and ordered by age, with 3-4 years separating each actor. Forbes Magazine's Star Currency ratings $(M=7.60 ; S D=0.25)$ were used as an index of familiarity to ensure that the actors were roughly equally well known. Seven common zoo animals were selected and arranged by their average adult weight, with increments of approximately $40 \mathrm{lbs}$. Seven perennial NBA all-star players were chosen and organized by height, with 2 inches separating each player. Finally, the seven largest countries, in terms of land mass (square $\mathrm{km}$ ), and the diameters of the eight planets in our solar system comprised the two uneven categories.

The study consisted of two parts: (1) a knowledge rating task, and (2) five free reconstruction of order tasks. In Part 1, subjects received the items in each of the five stimulus sets (separated by category) as well as instructions to provide a level of knowledge rating for each item on a scale from 1 to 5 with $1=$ not at all knowledgeable and $5=$ extremely knowledgeable. All subjects were first asked to rate their knowledge of the each NBA player, then the female actors, the countries, the zoo animals, and finally the planets. The exemplars of each category were randomly ordered. All knowledge ratings were completed before moving on to Part 2. 
In Part 2, subjects received five separate free reconstruction of order tasks (one at a time) in which they were asked to reconstruct the order of each item along the specified dimension. On the right side of the page, the exemplars were presented in a new random order (different from the order used in Part I) and paired with a letter (A-G or A-H). A column of numbers (1-7 or 1-8) paired with blank lines appeared next to each column of exemplars. Next to the first and the final numbered blanks were descriptors indicating the limits of the specified dimension (i.e., oldestyoungest; heaviest-lightest; tallest-shortest; largest-smallest). All subjects completed the reconstruction tasks in the same sequence (NBA players, female actors, countries, zoo animals, and planets).

\section{Procedure}

In each session, subjects were given a packet that contained instructions, the rating task, and the reconstruction of order tasks. The study was self-paced and began with subjects reading the instructions silently. In Part 1, subjects were asked to indicate their knowledge rating for each item. Next, they read the instructions for Part 2, which asked them to order the scrambled items according to the specified dimension. Specifically, subjects were to write the letter of the each exemplar (A-G or A-H) next to the appropriate numbered blank (1-7 or 1-8). Subjects were asked to fill in all the blanks, even if they had to guess. All subjects received identical packets with the same items from the same categories in same sequence. Upon completion of the fifth reconstruction of order task, the subjects were debriefed and thanked for their participation.

\section{Data Analysis}

The logic of the experiments works only if the subjects have knowledge of items. For example, if a particular person does not follow basketball and does not know the height of the players, then that person's data are not informative. We therefore excluded data from any person 
whose mean knowledge rating for a particular stimulus set was less than 2 . The results do not change substantively if a higher threshold is chosen (i.e., 3), but the data are less smooth due to the reduced number of observations. The mean knowledge ratings before excluding any data are shown in Figure 1.

\section{INSERT FIGURE 1 ABOUT HERE}

In episodic memory tests, it is usually clear which item is first (and therefore contributes to the primacy effect) and which item is last (and therefore contributes to the recency effect). In other types of tests, however, this can be less clear. For example, absolute judgment tasks can result in primacy and recency effects (e.g., Neath et al., 2006; Neath \& Brown 2006), and typically researchers will assume that the low value item is the "first" item and contributes to the primacy effect and the high value item is the "last" item and contributes to the recency effect. However, it could equally be the reverse. Below, we follow this convention and low value items (i.e., youngest, lightest, shortest, smallest) will correspond to primacy and high value items (i.e., oldest, heaviest, tallest, largest) will correspond to recency. Similarly, we also follow the convention of using the term "serial position function" despite the fact that we do not examine ordinal position; rather, we focus on location along the dimension of interest, i.e., age, weight, height, etc.

There is no generally accepted measure that indicates the presence of primacy or recency effects and whether one is observing a "real" serial position function or one that differs from the norm. Therefore, for each set of stimuli, we report four different assessments on the logic that although no single assessment is definitive, the convergence of all four assessments on the same conclusion will mitigate these issues. 
First, we examine whether the main effect of position along the relevant dimension is significant and also whether there is a significant quadratic component. The presence of a significant quadratic component does not necessarily indicate primacy and recency, but a nonsignificant quadratic component (all else being equal) does indicate the absence of one or both. Second, we examine the number of subjects who correctly ordered the first item more than the mid-list item (item 4), and the number who correctly ordered the final item more than the mid-list item. A significant result by a sign test is consistent with the presence of a primacy effect and a recency effect, respectively.

The final two assessments examine the pattern of errors, one quantitatively and the second qualitatively. In episodic memory tasks, there is a particular pattern of movement errors such that when an item is placed in an incorrect location, it is most likely recalled in a near position than a far position. That is, there should be many movement errors of a short distance and few movement errors of a long distance. For example, Brown, Preece and Hulme (2000, Figure 2) plotted movement errors from six different episodic experiments that varied in a number of ways (e.g., from immediate recall to a delay of 24 hours; from as few as 4 to as many as 16 items, etc.). In all cases, the pattern of movement errors consistently showed more shortthan long-distance movement errors than would be expected by chance (see also Quinlan, Neath, $\&$ Surprenant, in press, for another example). We examine the movement errors for consistency with these patterns that are observed in episodic tasks.

Finally, we compare the pattern of errors observed to the pattern predicted by SIMPLE (Brown et al. 2007; Neath \& Brown, 2006). Although no quantitative analysis is planned due to the reasons noted above, the shape of the observed error gradients should be similar to those generated by SIMPLE. 
The logic is that if all four of the above analyses converge on the same conclusion, there is good evidence that the serial position functions observed from general knowledge have the same characteristics as episodic serial position functions.

Results

Demonstration 1: Actors and Age

Overall, the mean knowledge rating for actors was $3.107(S D=1.009)$. Thirty-one out of 261 subjects had a mean knowledge rating of less than 2; with those data excluded, the mean knowledge rating became $3.321(S D=0.857)$.

Figure 2 (upper left) shows the proportion of actors correctly placed in order of age (left y-axis, white circles) and the mean knowledge rating for each actor (right y-axis, black triangles) for those subjects who gave a knowledge rating of 2 or higher. The memory data form a Ushaped serial position function and moreover, it is clear that the shape of this function is not simply a reflection of the knowledge data. For each subject, a correlation was computed between accuracy at each position and knowledge rating of each item. The mean correlation was $r(158)=$ 0.115 , which is not significant, $p>0.10 .^{1}$ This is consistent with the claim that the shape of the serial position function arises because of differential distinctiveness of the items along the dimension as opposed to differential knowledge of each individual item.

INSERT FIGURE 2 ABOUT HERE

\footnotetext{
${ }^{1}$ Correlations could not be computed for all subjects; for example, a subject may have given all items the same knowledge rating or may not have ordered any items correctly or may have ordered all items correctly.
} 
The proportion of actors correctly placed in order of age was analyzed by a repeated measures analysis of variance with position as a within-subjects factor. There was a significant effect of position, $F(6,1374)=12.065, M S E=0.173$, partial eta squared $=0.050, p<.001$. Importantly, the quadratic trend was also significant, $F(1,229)=45.375, M S E=0.193$, partial eta squared $=0.165, p<.001$. This is consistent with the claim that the observed serial position function includes both a primacy effect and a recency effect.

The next analysis examines the presence or absence of primacy and recency by comparing the number of subjects who recalled the first and last items better than mid-list items. Because there was only one trial per subject, this means that the subject placed the first item correctly and did not place the $4^{\text {th }}$ item correctly, or placed the last item correctly and did not place the $4^{\text {th }}$ item correctly. The number of subjects who correctly ordered Item 1 more accurately than Item 4 was 67 compared to 20 who showed the reverse pattern (there were 143 ties). This is significant by a sign test, $p<.001$, and is consistent with the claim that there was a primacy effect. The number of subjects who correctly ordered Item 7 more accurately than Item 4 was 88 compared to 15 who showed the reverse pattern (there were 127 ties). This is significant by a sign test, $p<.001$, and consistent with the claim that there was a recency effect.

The third analysis examines the pattern of order errors following the logic and procedure of Brown et al. (2000). When ordering the seven actors, it is possible to place a given actor in the correct position, or to place the actor anywhere from 1 to 6 positions away from the correct location. When item 1 is placed in position 2 , that is a movement error of 1 position. With a 7 item list, there are 12 ways in which a movement error of 1 could occur; 10 ways in which a movement error of 2 could occur; 8 ways in which a movement error of 3 could occur; and so on until 2 ways in which a movement error of 6 could occur (the first item is placed in position 7, or 
the last item is placed in position 1). One can compute the probability that each type of movement error would occur by chance, and this is shown in Figure 3 (upper left) as the solid line. In addition, one can determine the actual number of movement errors of each type, and this is shown in the same panel of Figure 3 as the open circles. The two patterns can be compared by a chi-square test which, if significant, indicates that the observed differs from what one would expect by chance. A chi-square test revealed that the observed differed significantly from what would be expected by chance, chi-square $(5, N=1124)=299.45, p<.001$. The results are indistinguishable from those observed with in episodic memory tests (see Brown et al., 2000, Figure 2) and are consistent with the claim that the pattern of errors differs from chance just like those observed in episodic memory tests.

INSERT FIGURE 3 ABOUT HERE

The fourth and final analysis concerns whether the shape of the error gradients resemble those predicted by SIMPLE. To produce predictions, the age of the actors was used as the underlying dimension. These ages were log transformed, and the similarity calculated using Equation 1. Then, a response matrix was calculated using Equation 2. The sole free parameter, $c$, was adjusted until the model produced a level of recall comparable to that observed in the data; in this case, $c=4.45$. The predictions of SIMPLE are shown as solid lines in Panel A of Figure 4; the corresponding data are shown as open circles. There are 49 data points and the correlation between the data and the model is 0.89 . The point is not that SIMPLE can simulate results of retrieval from semantic memory. Rather, the point we wish to emphasize is that the pattern of error gradients observed when people recall information from general knowledge closely resembles the error gradients of a model designed to account for episodic memory and which has 
successfully fit data from episodic memory. Despite the fact that SIMPLE was not designed to account for retrieval of information from general knowledge, the correspondence between the data and the model is remarkably similar. The major deviation is an under-prediction of performance of the item with the largest value. As will be seen below, this is observed in all of the other data sets.

All four analyses converge on the same conclusion: the results are consistent with the claim that the serial position function observed when people order actors based on age has the same characteristics as serial position functions observed in episodic recall. Both exhibit a primacy effect, both exhibit a recency effect, the pattern of errors differs systematically from what one would expect by chance, and the shape of the error gradients are similar.

\section{Demonstration 2: Animals and Weight}

Overall, the mean knowledge rating for the animals was $3.178(S D=0.991)$. Twenty-two out of 261 subjects had a mean knowledge rating of less than 2; with those data excluded, the mean knowledge rating became $3.329(S D=0.890)$.

Figure 2 (upper right) shows the proportion of animals correctly placed in order of weight (left y-axis, white circles) and the mean knowledge rating for each animal (right y-axis, black triangles) for those subjects who gave a knowledge rating of 2 or higher. The memory data clearly form a U-shaped serial position function and once again, it is clear that the shape of this function is not simply a reflection of the knowledge data. The mean correlation between accuracy at each position and knowledge rating of each item, $r(165)=0.127$, was not significant, $p>0.10$. 
The proportion of animals correctly placed in order of weight was analyzed by a repeated measures analysis of variance with position as a within-subjects factor. There was a significant effect of position, $F(6,1428)=52.027, M S E=0.174$, partial eta squared $=0.179, p<.001$. Importantly, the quadratic trend was also significant, $F(1,238)=215.245, M S E=0.192$, partial eta squared $=0.475, p<.001$. These results are consistent with the claim of a U-shaped serial position function.

The number of subjects who correctly ordered Item 1 more accurately than Item 4 was 122 compared to 14 who showed the reverse pattern (there were 103 ties). This is significant by a sign test, $p<.001$, and is consistent with the the claim that there was a primacy effect. The number of subjects who correctly ordered Item 7 more accurately than Item 4 was 116 compared to 12 who showed the reverse pattern (there were 111 ties). This is significant by a sign test, $p<$ .001 , and is consistent with the claim that there was a recency effect.

The movement errors are shown as open circles in Figure 3 (upper right), with chance performance shown as the solid line. A chi-square test on the pattern of movement errors revealed that the observed differed significantly from what would be expected by chance, chisquare $(5, N=1060)=568.40, p<.001$. This is consistent with the claim that the pattern of errors differs from chance just like those observed in episodic memory tests.

To produce predictions from SIMPLE, the weight of the animals was used as the underlying dimension and the sole free parameter, $c$, was set to 3.15. The predictions of SIMPLE are shown as solid lines in Panel B of Figure 4; the corresponding data are shown as open circles. There are 49 data points and the correlation between the data and the model is 0.75 . Although the pattern of errors observed again resembles the pattern of errors predicted, the data diverge more from the predictions than was the case for the actor data. In particular, both the cougar and the 
reindeer show contrary error patterns. It should be noted, however, that subjects indicated they had the least knowledge about these animals, with ratings of 2.958 and 3.097 respectively, compared to mean rating of 3.450 for the remaining animals.

Despite this, all four analyses once again converge on the same conclusion: the results are consistent with the assertion that the serial position function observed when people order animals based on weight has the same characteristics as the serial position functions observed in episodic recall.

Demonstration 3: Basketball Players and Height

Overall, the mean knowledge rating for basketball players was $2.289(S D=1.128)$. One hundred and nineteen out of 261 subjects had a mean knowledge rating of less than 2; with those data excluded, the mean knowledge rating became $3.182(S D=0.948)$. Overall, the subjects indicated they were less knowledgeable about basketball than any of the other four stimulus sets.

The large number of subjects who indicated a knowledge rating of less than 2 for the basketball players allows for a control test that is not possible with the other stimuli: These subjects should be ordering the basketball players at chance levels and there should no effect of position. For a seven item list, chance performance is 0.1429 . The mean proportion correct for these subjects was 0.1369 , which is not significantly different from chance, $t(118)=-0.377, p>$ 0.70. In addition, a repeated measures analysis of variance with position as a within subjects factor did not find a significant effect of position, $F(6,708)=1.580, M S E=0.102$, partial eta squared $=0.013, p>0.15$. The quadratic trend was similarly not significant, $F(1,118)=0.302$, $M S E=0.133$, partial eta squared $=0.003, p>.50$. The number of subjects who correctly ordered Item 1 more accurately than Item 4 was 21 compared to 18 who showed the reverse (there were 
80 ties). This is not significant by a sign test, $p>.70$, and is consistent with the claim that there is no primacy effect. The number of subjects who correctly ordered Item 7 more accurately than Item 4 was 9 compared to 17 who showed the reverse (there were 93 ties). This is not significant by a sign test, $p>.15$. This is consistent with the claim that there is no recency effect. If subjects indicate little or no knowledge of a set of stimuli, their accuracy in ordering the stimuli should be at chance levels, and these analyses confirm that. Some knowledge is required in order to do the task, but as the non-significant correlations between knowledge rating and memory performance indicate, it is not knowledge that is determining the shape of the serial position function.

Figure 2 (lower left) shows the proportion of basketball players correctly placed in order of height (left y-axis, white circles) and the mean knowledge rating for each basketball player (right y-axis, black triangles) for those subjects who gave a knowledge rating of 2 or higher. The memory data do not show a U-shaped serial position function; rather, there appears to be no primacy effect. However, it is clear that the shape of this function is not simply a reflection of the knowledge data. The mean correlation between accuracy at each position and knowledge rating of each item, $r(78)=-0.031$, was not significant, $p>0.75$.

The proportion of basketball players correctly placed in order of height was analyzed by a repeated measures analysis of variance with position as a within-subjects factor. There was a significant effect of position, $F(6,846)=2.459, M S E=0.135$, partial eta squared $=0.017, p<$ .05. Importantly, the quadratic trend was also significant, $F(1,141)=4.712, M S E=0.167$, partial eta squared $=0.032, p<.05$. As noted above, the presence of a significant quadratic trend does not necessarily indicate that both primacy and recency effects are present, as the next analysis shows. 
The number of subjects who correctly ordered Item 1 more accurately than Item 4 was 26 compared to 23 who showed the reverse (there were 93 ties). This is not significant by a sign test, $p>.75$. This indicates the absence of a primacy effect and, to anticipate, is the only analysis from those of all five sets of stimuli that is not consistent with the claim that the serial position functions observed resemble those seen in episodic tasks. Although there was no evidence of a primacy effect, there was evidence of a recency effect. The number of subjects who correctly ordered Item 7 more accurately than Item 4 was 25 compared to 11 who showed the reverse pattern (there were 106 ties), which is significant by a sign test, $p<.05$.

The movement errors are shown as open circles in Figure 3 (lower left), with chance performance shown as the solid line. A chi-square test on the pattern of movement errors revealed that the observed differed significantly from what would be expected by chance, chisquare $(5, \mathrm{~N}=675)=96.39, p<.001$. This is consistent with the claim that the pattern of errors differs from chance just like those observed in episodic memory tests.

To produce predictions from SIMPLE, the weight of the animals was used as the underlying dimension and the sole free parameter, $c$, was set to 16.0. The predictions of SIMPLE are shown as solid lines in Panel C of Figure 4; the corresponding data are shown as open circles. There are 49 data points and the correlation between the data and the model is 0.78 . Once again, the pattern of the errors remains remarkably similar to the pattern predicted by SIMPLE.

All but one of the analyses of the data for basketball players converged on the conclusion that the results are consistent with the claim that the serial position function observed when people order basketball players based on weight has the same characteristics as the serial position functions observed in both immediate and delayed episodic recall. The exception was lack of evidence for a primacy effect. As noted above, the terms "primacy" and "recency" are arbitrary 
with respect to these data, and it is a primacy effect that is absent rather than a recency effect only because of the convention of ordering the basketball players from shortest to tallest.

\section{Demonstration 4: Countries and Land Mass}

Overall, the mean knowledge rating for countries was $3.282(S D=0.857)$. Nine out of 261 subjects had a mean knowledge rating of less than 2; with those data excluded, the mean knowledge rating became $3.346(S D=0.799)$.

Figure 2 shows (lower middle) the proportion of countries correctly placed in order of land mass (left y-axis, white circles) and the mean knowledge rating for each country (right yaxis, black triangles) for those subjects who gave a knowledge rating of 2 or higher. The figure shows a U-shaped serial position function for the memory data, albeit an unusual-looking one because the mid-list items are more closely spaced together on the dimension. The figure also shows a manipulation check of the level of knowledge rating: The mean knowledge rating for the United States (the location of the subjects) was 4.78, higher than for any other country. Again, the memory data are not a simple function of the knowledge data. The mean correlation between accuracy at each position and knowledge rating of each item, $r(191)=0.011$, was not significant, $p>0.80$

The proportion of countries correctly placed in order of land mass was analyzed by a repeated measures analysis of variance with position as a within-subjects factor. There was a significant effect of position, $F(6,1506)=33.135, M S E=0.160$, partial eta squared $=0.117, p<$ .01. Importantly, the quadratic trend was also significant, $F(1,251)=101.158, M S E=0.177$, partial eta squared $=0.287, p<.001$. These results are consistent with the claim of a U-shaped serial position function 
The number of subjects who correctly ordered Item 1 more accurately than Item 4 was 62 compared to 23 who showed the reverse pattern (there were 167 ties), which is significant by a sign test, $p<.001$, and is consistent with the claim that there was a primacy effect. The number of subjects who correctly ordered Item 7 more accurately than Item 4 was 120 compared to 7 who showed the reverse pattern (there were 125 ties). This is significant by a sign test, $p<.001$, and is consistent with the claim that there was a recency effect.

The movement errors are shown as open circles in Figure 3 (lower middle), with chance performance shown as the solid line. A chi-square test on the pattern of movement errors revealed that the observed differed significantly from what would be expected by chance, chisquare $(5, N=1220)=191.10, p<.001$. This is consistent with the claim that the pattern of errors differs from chance just like those observed in episodic memory tests.

To produce predictions from SIMPLE, the landmass of the countries was used as the underlying dimension and the sole free parameter, $c$, was set to 1.75. The predictions of SIMPLE are shown as solid lines in Panel D of Figure 4; the corresponding data are shown as open circles. There are 49 data points and the correlation between the data and the model is 0.67 . For the seven countries with the largest landmass, the spacing between the items is not even; in particularly, the mid-list items are all very similar in size and this is apparent in both the order data (see Figure 2) as well as in the pattern of the error data (see Figure 4). Nonetheless, the pattern of the errors remains similar to the pattern predicted by SIMPLE.

All four analyses of the data for countries converged on the conclusion that the results are consistent with the claim that the serial position function observed has the same characteristics as the serial position functions observed in both immediate and delayed episodic recall. 


\section{Demonstration 5: Planets and Diameter}

Overall, the mean knowledge rating for planets was $2.953(S D=0.971)$. Thirty-seven out of 261 subjects had a mean knowledge rating of less than 2; with those data excluded, the mean knowledge rating became $3.191(S D=0.832)$.

Figure 2 (lower right) shows the proportion of planets correctly placed in order of diameter size (left y-axis, white circles) and the mean knowledge rating for each actor (right yaxis, black triangles) for those subjects who gave a knowledge rating of 2 or higher. The memory data show a U-shaped serial position function, again distorted due to the variation of the planets along the dimension. The knowledge data show a manipulation check of knowledge rating: The mean knowledge rating for Earth (the location of the subjects) was 4.69 , higher than for any other planet. As with the other stimuli, the shape of the memory data is not simply a reflection of the knowledge data. The mean correlation between accuracy at each position and knowledge rating of each item, $r(154)=0.003$, was not significant, $p>0.95$.

The proportion of planets correctly placed in order of diameter was analyzed by a repeated measures analysis of variance with position as a within-subjects factor. There was a significant effect of position, $F(7,1561)=33.934, M S E=0.157$, partial eta squared $=0.132, p<$ .001 . Importantly, the quadratic trend was also significant, $F(1,223)=98.963, M S E=0.198$, partial eta squared $=0.307, p<.001$.

The number of subjects who correctly ordered Item 1 more accurately than Item 4 was 55 compared to 25 who showed the reverse (there were 144 ties). This is significant by a sign test, $p$ $<.01$, and is consistent with the assertion that there was a primacy effect. The number of subjects who correctly ordered Item 8 more accurately than Item 4 was 94 compared to 15 who showed 
the reverse pattern (there were 115 ties). This is significant by a sign test, $p<.001$ and is consistent with the assertion that there was a recency effect.

The movement errors are shown as open circles in Figure 3 (lower right), with chance performance shown as the solid line. A chi-square test on the pattern of movement errors revealed that the observed differed significantly from what would be expected by chance, chisquare $(6, N=1204)=254.10, p<.001$. This is consistent with the claim that the pattern of errors differs from chance just like those observed in episodic memory tests.

To produce predictions from SIMPLE, the diameter of the planets was used as the underlying dimension and the sole free parameter, $c$, was set to 0.8. The predictions of SIMPLE are shown as solid lines in Panel E of Figure 4; the corresponding data are shown as open circles. There are 64 data points and the correlation between the data and the model is 0.76 . As with the other data, there are systematic deviations from the prediction, particularly with the largest value item. Despite that consistent discrepancy, the pattern of the errors resembles the pattern predicted by SIMPLE.

All four analyses of the data for planets converged on the conclusion that the results are consistent with the claim that the serial position function observed has the same characteristics as the serial position functions observed in both immediate and delayed episodic recall.

\section{General Discussion}

For four of the five stimulus sets, all four of the analyses converge on the same conclusion: the serial position functions observed when people order items based on general knowledge exhibit primacy effects, recency effects, and the same pattern of movement errors compared to when people immediately recall as list of items or recall a list of items after a delay 
in an episodic task. The fifth stimulus set, ordering basketball players based on height, lacked only evidence for a primacy effect; all other analyses (e.g., evidence for recency, pattern of errors, shape of error gradient) were consistent with observing a serial position function. As noted above, the subjects indicated that of the five stimulus sets they were least knowledgeable about basketball, with nearly half of the subjects giving a mean rating less than 2 .

The results are consistent with the growing number of studies that report serial position functions in tasks thought to tap semantic, as opposed to episodic, memory (e.g., Crowder, 1993; Healy et al., 2000; Healy \& Parker, 2001; Kelley et al., 2013, 2014; Maylor, 2002; Neath \& Saint-Aubin, 2011; Overstreet \& Healy, 2011; Roediger \& Crowder, 1976). Even if one discounts the data from the basketball payers due to lack of a primacy effect, there remain demonstrations of serial position effects with 8 different classes of stimuli: political figures, lyrics, books, movies, actors, animals, countries, and planets.

One might still object that the shape of the functions reported here seem to show more variability than the serial position functions found in episodic tasks. To the extent that this is the case, we think it because episodic tasks typically use stimuli with limited variation along the main dimension (e.g., they use words shown at a rate of 1 item per second). However, the shapes can change quite dramatically when the spacing along the dimension is manipulated, including selectively enhancing primacy or recency, selectively reducing primacy or recency, and selectively changing the low point in the function. For example, the serial position function can change from showing recency to showing primacy with increasing delay (e.g., Bjork, 2001; Neath, 1993); from showing a U-shaped function to one closer to a straight line as the items are more proportionally spaced (e.g., Neath \& Crowder, 1990); and from showing pronounced recency to no recency to pronounced recency as immediate free recall becomes delayed free 
recall becomes continual distractor recall (e.g., Bjork \& Whitten, 1974). It is important to note that the claim that serial position functions obtain in both episodic and semantic memory because of the same principle does not necessarily mean that all such functions should look identical. Rather, it means that performance will be a function of the relative distinctiveness of the set of items along the main dimension of interest. It also means that when either the dimensions differ or the locations along the dimension differ, the functions can look quite dissimilar.

According to the relative distinctiveness principle (Surprenant \& Neath, 2009), serial position functions arise when items are ordered along one or more dimensions, but the particular dimension(s) can vary. For example, in episodic tasks, the dimension is frequently temporal (i.e., relative time), but need not be; items can be ordered along perceptual dimensions (Neath et al., 2006) or a position dimension (Surprenant et al., 2006) or any other dimension that is useful and relevant to the task. In semantic tasks, the ordering is less likely to be temporally based and more likely to be a nominal or logical ordering (e.g., the second verse follows the first verse); time per $s e$ is not a factor. In the case of the stimuli used here, they are presumed to be ordered along dimensions of age, weight, height, area, and diameter. Of course, if stimuli are not ordered along a dimension, then serial position functions will not be observed. For instance, such functions should not be observed when recalling the names of the seven dwarves in the Disney film (see Meyer \& Hilterbrand, 1984) but should be observed when recalling the release order of Disney films (Kelley et al., 2013).

SIMPLE did not, of course, produce excellent quantitative fits, nor should anyone have expected this. SIMPLE was not designed with recall of general knowledge in mind nor does it address how knowledge in general might be stored and retrieved. Moreover, SIMPLE has only a single free parameter, $c$, which affects the degree to which more distant items affect 
distinctiveness. What SIMPLE does do is make a prediction about how accurately those items can be ordered once they are retrieved, and SIMPLE has been shown to produce accurate predictions for both episodic and some semantic data (e.g., Brown et al., 2007; Kelley et al., 2013; Neath, 2010; Neath \& Brown, 2006; Neath \& Saint-Aubin, 2011). The purpose of using SIMPLE was to enable a comparison of the shape of the error gradients. The chi-square tests showed that the movement errors differed significantly from chance, just like those observed in episodic serial position functions, but the chi-square test does not say that the pattern resembles that found in episodic tasks. The comparison with the predictions of SIMPLE allows for such an assessment.

Of particular interest are the discrepancies. Some, such as those involving reindeer and seals, are likely a result of less knowledge. Others, however, may be informative in the further development of SIMPLE. In all cases, SIMPLE under predicted performance of the item with the largest value, and we have no explanation currently for this result. As noted above, it is ambiguous whether this is an issue with predicting "primacy" or "recency" because unlike in the episodic case, there is no clear "first" item. Regardless, it is a weakness in SIMPLE that requires further examination.

The results are consistent with the idea that there exist general principles of memory which apply regardless the hypothesized underlying memory system (Surprenant \& Neath, 2009). In this case, the principle is the relative distinctiveness principle, which describes how the serial position function arises from differential relative distinctiveness of items when they are ordered along some sensible dimension. Whereas it is not possible to prove that a principle always applies everywhere, it is trivial to demonstrate that it does not apply. It was entirely possible that ordering items retrieved from general knowledge would not result in a serial 
position function. At the very least, such a finding would have placed limits on the principle's applicability. Instead, all five stimulus sets produced a serial position function and error gradients reminiscent of those seen in episodic memory, just as the relative distinctiveness principle predicts. 


\section{References}

Atkinson, R. C., \& Shiffrin, R. M. (1968). Human memory: A proposed system and its control processes. In K. W. Spence \& J. T. Spence (Eds.), The psychology of learning and motivation, Vol. 2 (pp. 89-195). New York: Academic Press.

Bjork, R. A. (2001). Recency and recovery in human memory. In H. L. Roediger, III, J. S. Nairne, I. Neath, and A. M. Surprenant (Eds.), The nature of remembering: Essays in honor of Robert G. Crowder (pp. 211-232). New York: APA.

Bjork, R. A., \& Whitten, W. B. (1974). Recency-sensitive retrieval processes in long-term free recall. Cognitive Psychology, 6, 173-189.

Brown, G. D. A., Neath, I., \& Chater, N. (2007). A temporal ratio model of memory. Psychological Review, 114, 539-576.

Brown, G. D. A., Preece, T., \& Hulme, C. (2000). Oscillator-based memory for serial order. Psychological Review, 107, 127-181.

Crowder, R. G. (1993). Short-term memory: Where do we stand? Memory \& Cognition, 21, 142145.

Davelaar, E. J., Goshen-Gottstein, Y., Ashkenazi, A., Haarmann, H. J., \& Usher, M. (2005). The demise of short-term memory revisited: Empirical and computational investigations of recency effects. Psychological Review, 112, 3-42.

Glanzer, M. (1972). Storage mechanisms in recall. In G. H. Bower \& J. T. Spence (Eds.), The psychology of learning and motivation, Vol. 5 (pp. 129-153). New York: Academic Press.

Glanzer, M., \& Cunitz, A. R. (1966). Two storage mechanisms in free recall. Journal of Verbal Learning and Verbal Behavior, 5, 351-360. 
Glenberg, A. M., Bradley, M. M., Kraus, T. A., \& Renzaglia, G. J. (1983). Studies of the longterm recency effect: Support for a contextually guided retrieval hypothesis. Journal of Experimental Psychology: Learning, Memory, and Cognition, 9, 231-255.

Greene, R. L. (1986). A common basis for recency effects in immediate and delayed recall. Journal of Experimental Psychology: Learning, Memory, and Cognition, 12, 413-418.

Healy, A. F. (1974). Separating item from order information in short-term memory. Journal of Verbal Learning and Verbal Behavior, 13, 644-655.

Healy, A. F., Havas, D. A., \& Parker, J. T. (2000). Comparing serial position effects in semantic and episodic memory using reconstruction of order tasks. Journal of Memory \& Language, 42, 147-167.

Healy, A. F., \& Parker, J. T. (2001). Serial position effects in semantic memory: Reconstruction the order of U.S. Presidents and vice-presidents. In H. L. Roediger, J. S. Nairne, I. Neath, \& A. Surprenant (Ed.), The nature of remembering: Essays in honor of Robert $G$. Crowder (pp. 171-188). Washington, DC: American Psychological Association.

Kelley, M. R., Neath, I., \& Surprenant, A. M. (2013). Three more semantic serial position functions and a SIMPLE explanation. Memory \& Cognition, 41, 600-610

Kelley, M. R., Neath, I. \& Surprenant, A. M. (2014). A remember/know analysis of the semantic serial position function. American Journal of Psychology, 127, 137-145

Maylor, E. A. (2002). Serial position effects in semantic memory: Reconstructing the order of verses of hymns. Psychonomic Bulletin \& Review, 9, 816-820.

Meyer, G. E., \& Hilterbrand, K. (1984). Does it pay to be "Bashful"? The Seven Dwarfs and long-term memory. American Journal of Psychology, 97, 47-55. 
Nairne, J. S. (1992). The loss of positional certainty in long-term memory. Psychological Science, 3, 199-202.

Neath, I. (1993). Distinctiveness and serial position effects in recognition. Memory \& Cognition, $21,689-698$.

Neath, I. (2010). Evidence for similar principles in episodic and semantic memory: The presidential serial position function. Memory \& Cognition, 38, 659-666.

Neath, I., \& Brown, G. D. A. (2006). SIMPLE: Further applications of a local distinctiveness model of memory. In B. H. Ross (Ed.), The psychology of learning and motivation (pp. 201-243). San Diego, CA: Academic Press.

Neath, I., \& Crowder, R. G. (1990). Schedules of presentation and distinctiveness in human memory. Journal of Experimental Psychology: Learning, Memory, and Cognition, 16, $316-327$.

Neath, I., \& Saint-Aubin, J. (2011). Further evidence that similar principles govern recall from episodic and semantic memory: The Canadian prime ministerial serial position function. Canadian Journal of Experimental Psychology, 65, 77-83.

Neath, I., Brown, G. D. A., McCormack, T., Chater, N., \& Freeman, R. (2006). Distinctiveness models of memory and absolute identification: Evidence for local, not global, effects. Quarterly Journal of Experimental Psychology, 59, 121-135.

Overstreet, M. F., \& Healy, A. F. (2011). Item and order retention in semantic memory: Students" retention of the "CU fight song" lyrics. Memory \& Cognition, 39, 251-259. Postman, L., \& Phillips, L. W. (1965). Short-term temporal changes in free recall. Quarterly Journal of Experimental Psychology, 17, 132-138. 
Quinlan, J. A., Neath, I., \& Surprenant, A. M. (in press). Positional uncertainty in the BrownPeterson paradigm. Canadian Journal of Experimental Psychology.

Roediger, H. L. III, \& Crowder, R. G. (1976). A serial position effect in recall of United States presidents. Bulletin of the Psychonomic Society, 8, 275-278.

Roediger, H. L., \& DeSoto, K. A. (2014). Forgetting the presidents. Science, 346, 1106-1109.

Sehulster, J. R. (1989). Content and temporal structure of autobiographical knowledge: Remembering 25 seasons at the Metropolitan Opera. Memory \& Cognition, 17, 590-606.

Shepard, R. N. (1987). Toward a universal law of generalization for psychological science. Science, 237, 1317-1323.

Surprenant, A. M., \& Neath, I. (2009). Principles of memory. New York: Psychology Press.

Surprenant, A. M., Neath, I., \& Brown, G. D. A. (2006). Modeling age-related differences in immediate memory using SIMPLE. Journal of Memory and Language, 55, 572-586.

Tulving, E. (1972). Episodic and semantic memory. In E. Tulving \& W. Donaldson (Eds.), Organization of memory (pp. 381-403). New York: Academic Press.

Tulving, E. (1983). Elements of episodic memory. New York: Oxford.

Tulving, E. (1985). Memory and consciousness. Canadian Psychology 26, 1-12.

Waugh, N. C., \& Norman, D. A. (1965). Primary memory. Psychological Review, 72, 89-104. 


\section{Author Note}

This research was supported, in part, by grants from NSERC to I.N. and A.M.S. We thank Kent Grote for his assistance during data collection. Correspondence may be addressed to Matthew R. Kelley (kelley@lakeforest.edu) or Ian Neath (ineath@mun.ca). 
Appendix

Actors: Age (increments of approximately 3-4 years)

\begin{tabular}{|l|c|c|c|c|}
\hline Name & Initials & Age & Forbes Star Currency & Forbes Rank \\
\hline Keira Knightly & KK & 28 & 7.78 & 8 \\
\hline Anne Hathaway & AH & 31 & 7.27 & 21 \\
\hline Kate Hudson & KH & 34 & 7.27 & 21 \\
\hline Charlize Theron & CT & 38 & 8.00 & 6 \\
\hline Cameron Diaz & CD & 41 & 7.72 & 12 \\
\hline Jennifer Aniston & JA & 45 & 7.58 & 14 \\
\hline Sandra Bullock & SB & 49 & 7.60 & \\
\hline
\end{tabular}

Animals: Weight (increments of approximately 40lbs)

\begin{tabular}{|l|c|}
\hline Animal & Weight (lbs) \\
\hline Chimpanzee & 100 \\
\hline Cougar & 140 \\
\hline Seal & 187 \\
\hline Reindeer & 220 \\
\hline Tiger & 264 \\
\hline Gorilla & 308 \\
\hline Black Bear & 340 \\
\hline
\end{tabular}


Basketball Players: Height (increments of approximately 2 in)

\begin{tabular}{|l|c|c|c|c|}
\hline Name & Initials & Height & \# All Star Games & Salary \\
\hline Chris Paul & CP & $6^{\prime} 0^{\prime \prime}$ & 7 & $18.1 \mathrm{M}$ \\
\hline Tony Parker & TP & $6^{\prime} 2^{\prime \prime}$ & 6 & $12.5 \mathrm{M}$ \\
\hline Dwayne Wade & DW & $6^{\prime} 4^{\prime \prime}$ & 10 & $18.6 \mathrm{M}$ \\
\hline Kobe Bryant & KB & $6^{\prime} 6^{\prime \prime}$ & 16 & $30 \mathrm{M}$ \\
\hline LeBron James & LJ & $6^{\prime} 8^{\prime \prime}$ & 10 & $19 \mathrm{M}$ \\
\hline Blake Griffin & BG & $6^{\prime} 10^{\prime \prime}$ & 4 & $7.2 \mathrm{M}$ \\
\hline Tim Duncan & TD & $7^{\prime} 0^{\prime \prime}$ & & $9.6 \mathrm{M}$ \\
& & & & \\
\hline
\end{tabular}

Countries: Land Mass (square kilometers)

\begin{tabular}{|l|r|}
\hline Country & Land Mass (sq. km) \\
\hline India & $3,287,590$ \\
\hline Australia & $7,686,850$ \\
\hline Brazil & $8,511,965$ \\
\hline China & $9,596,960$ \\
\hline United States & $9,629,091$ \\
\hline Canada & $9,976,140$ \\
\hline Russia & $1,7075,200$ \\
\hline
\end{tabular}


Planets: Diameter (kilometers)

\begin{tabular}{|l|r|}
\hline Planet & Diameter (km) \\
\hline Mercury & 2,300 \\
\hline Mars & 6,800 \\
\hline Venus & 12,100 \\
\hline Earth & 12,800 \\
\hline Neptune & 49,500 \\
\hline Uranus & 51,100 \\
\hline Saturn & 125,000 \\
\hline Jupiter & 143,000 \\
\hline
\end{tabular}




\section{Figure Captions}

Figure 1. The mean knowledge rating for each stimulus set. Note: $N=261$ for each column. Error bars show the standard error of the mean.

Figure 2. The proportion of times each item (actors, upper left; animals, upper right; basketball players, lower left; countries, lower center; planets, lower right) was placed in the correct order on the relevant dimension (white circles, left y-axis) and the mean knowledge rating excluding those subjects whose mean rating was less than 2 (black triangles, right y-axis).

Figure 3. The proportion of errors as a function of the distance between the original position and the reported position (data points) and chance performance (line) for each type of item (actors, upper left; animals, upper right; basketball players, lower left; countries, lower center; planets, lower right).

Figure 4. The proportion of times each item was remembered as occurring in each possible position. The open circles are the data, and the lines represent the prediction of SIMPLE. Panel A shows the data for actors, Panel B shows animals, Panel C shows basketball players, Panel D shows countries, and Panel E shows planets. 
Figure 1

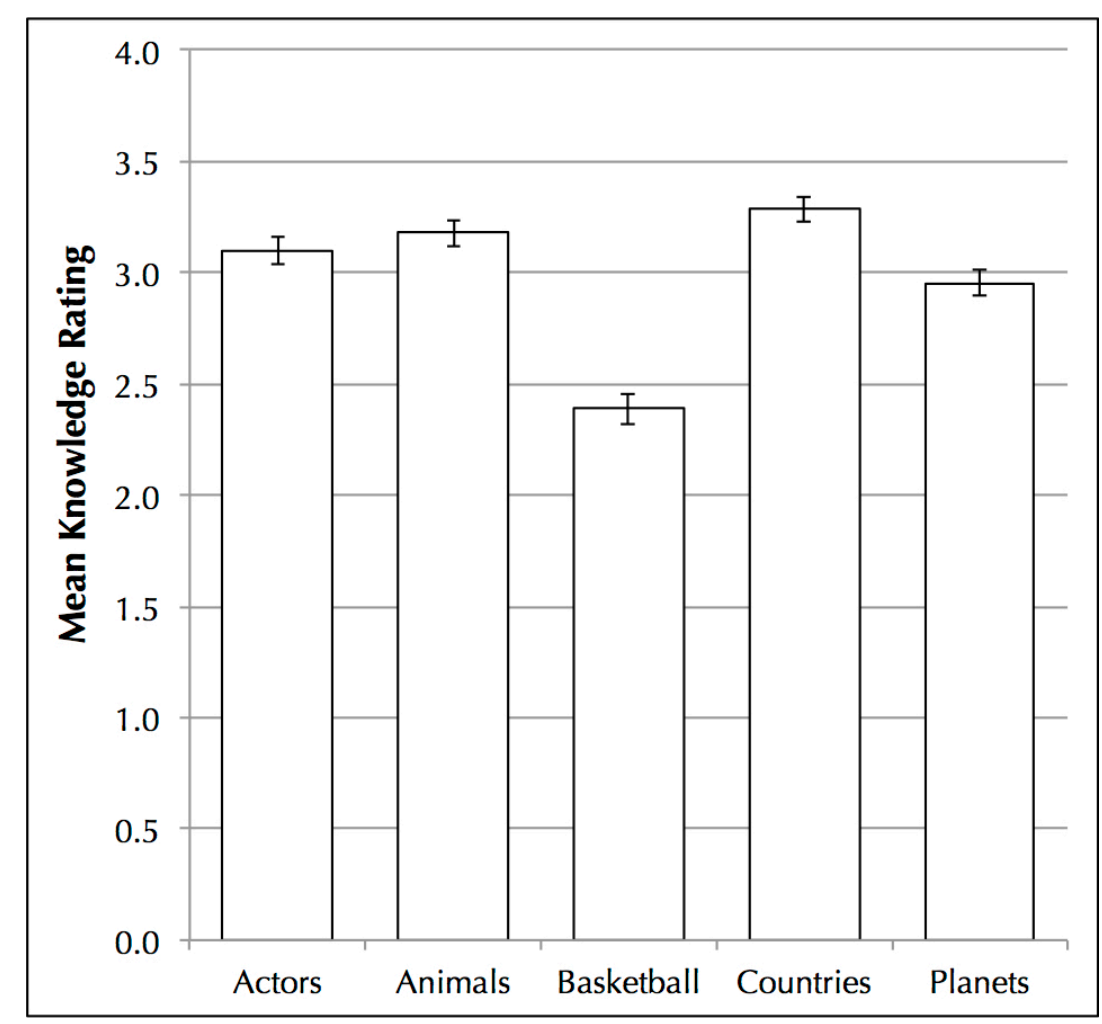


Figure 2
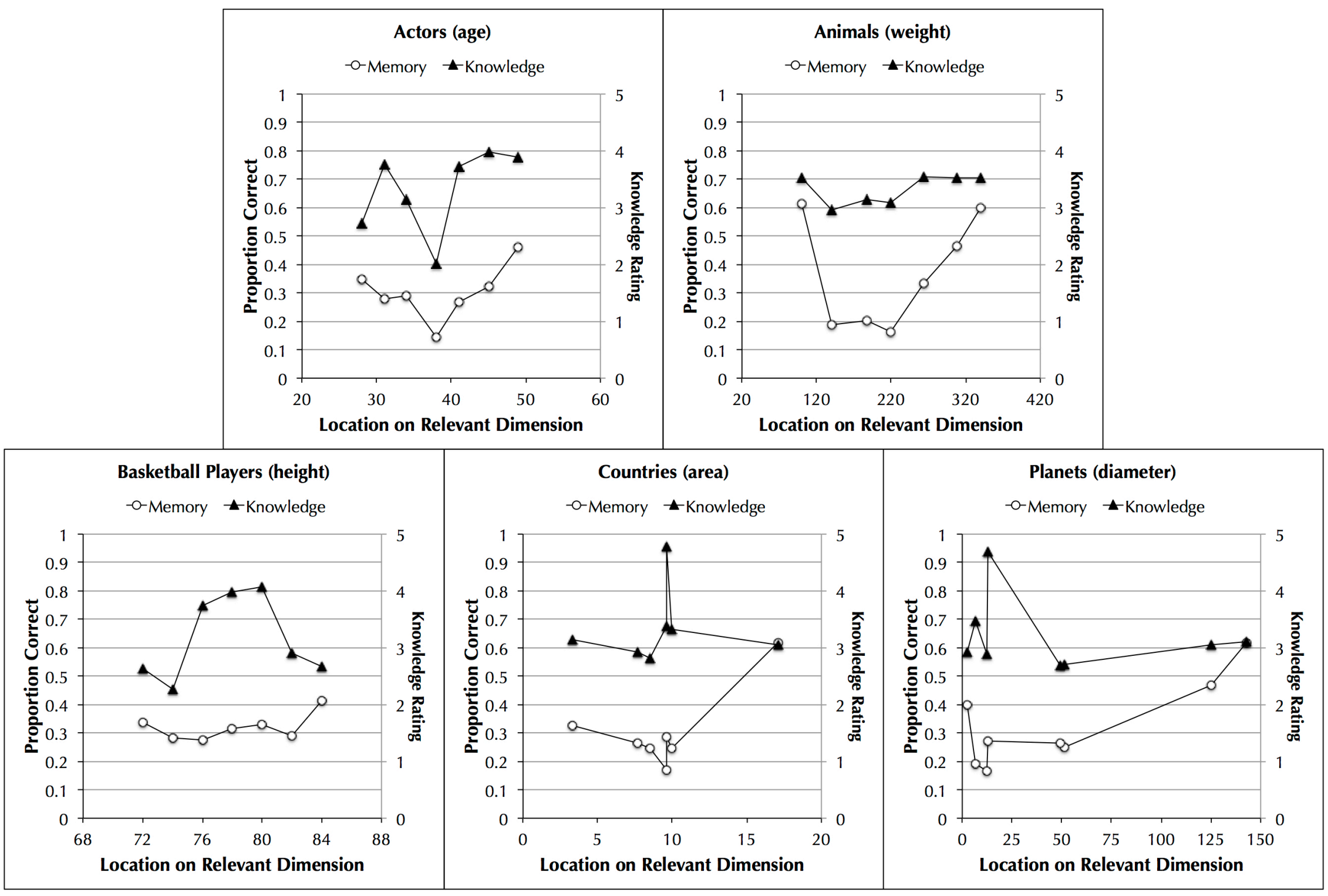
Figure 3

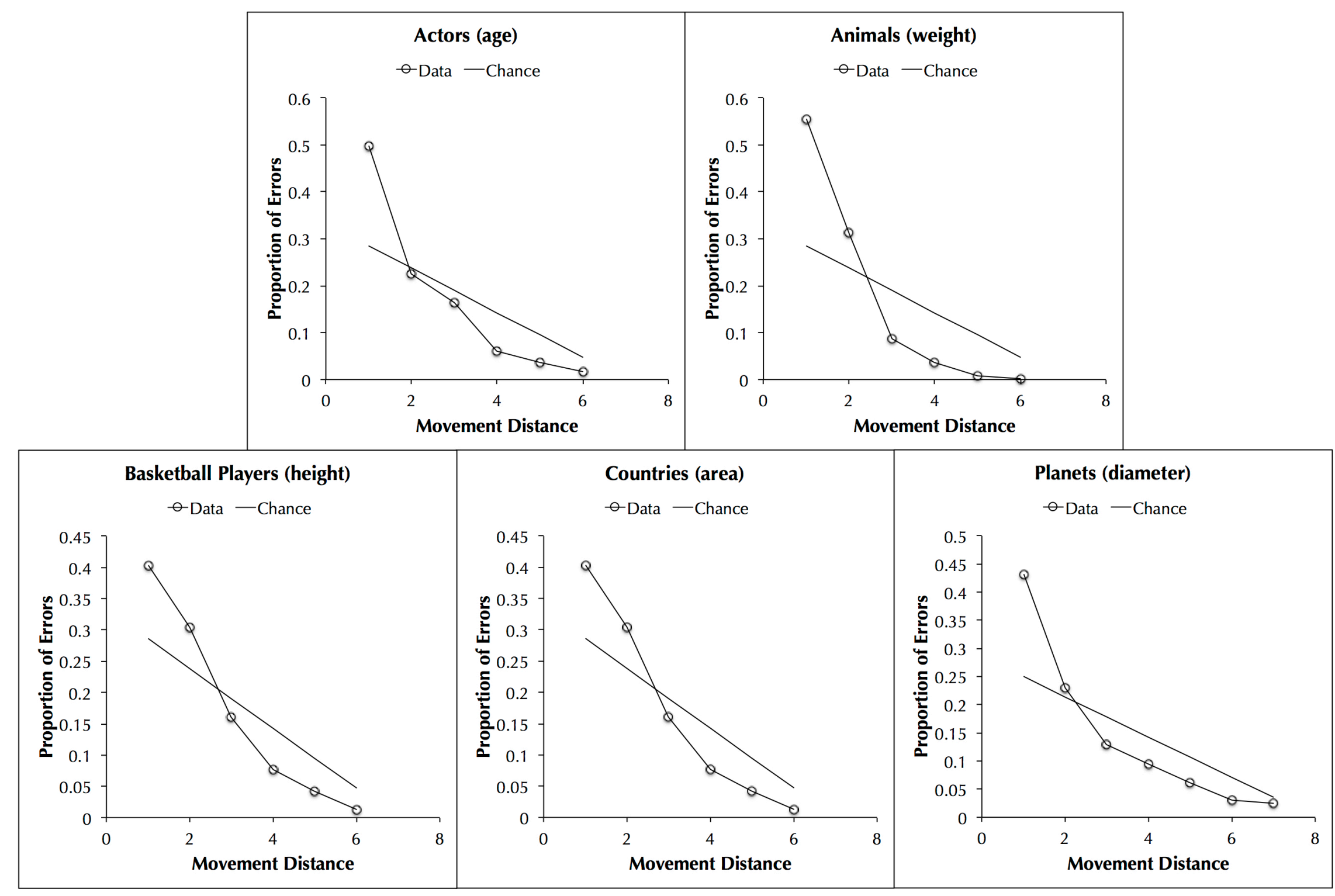


Figure 4 Panel A

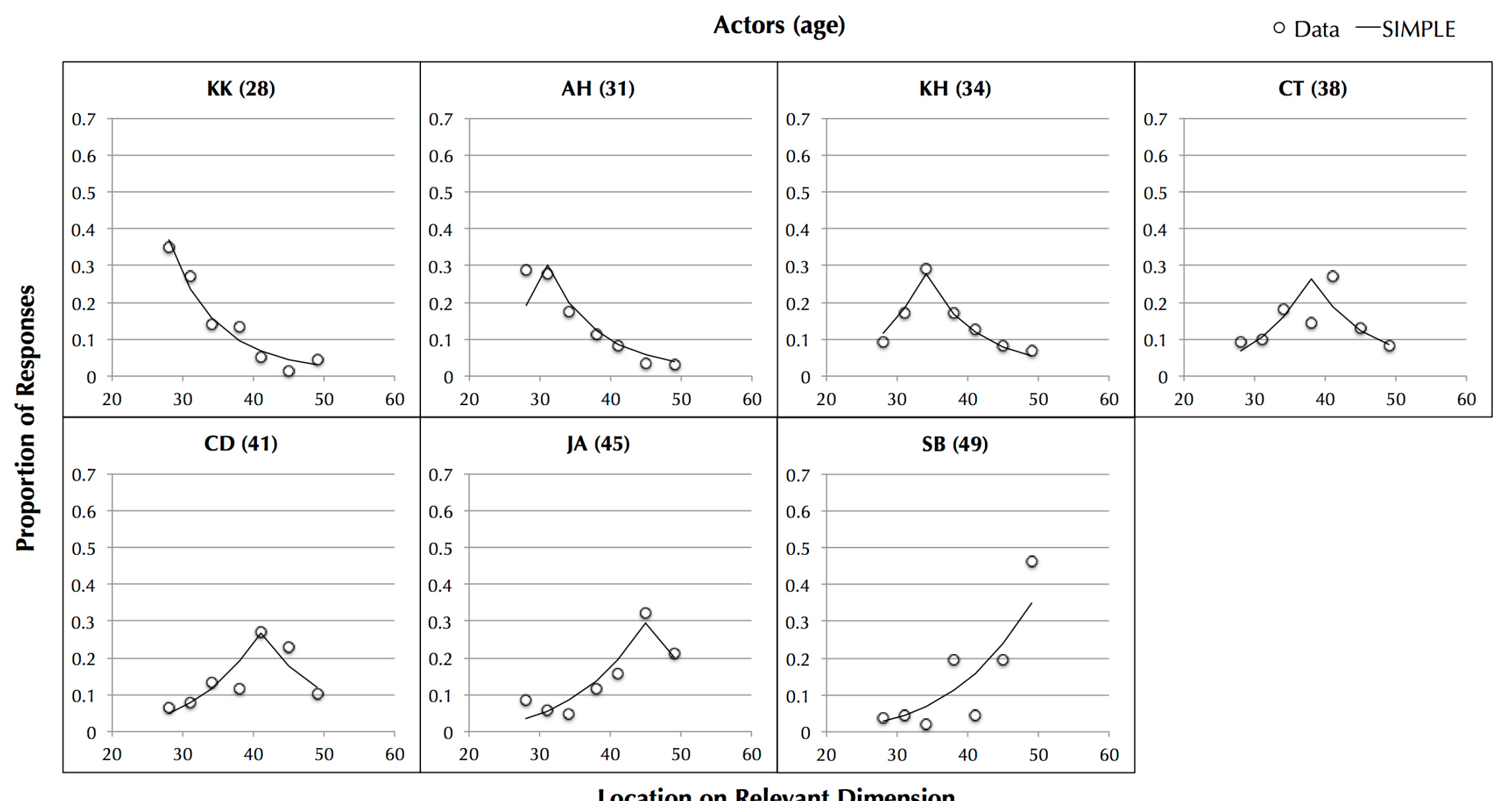

Location on Relevant Dimension 
Figure 4 Panel B

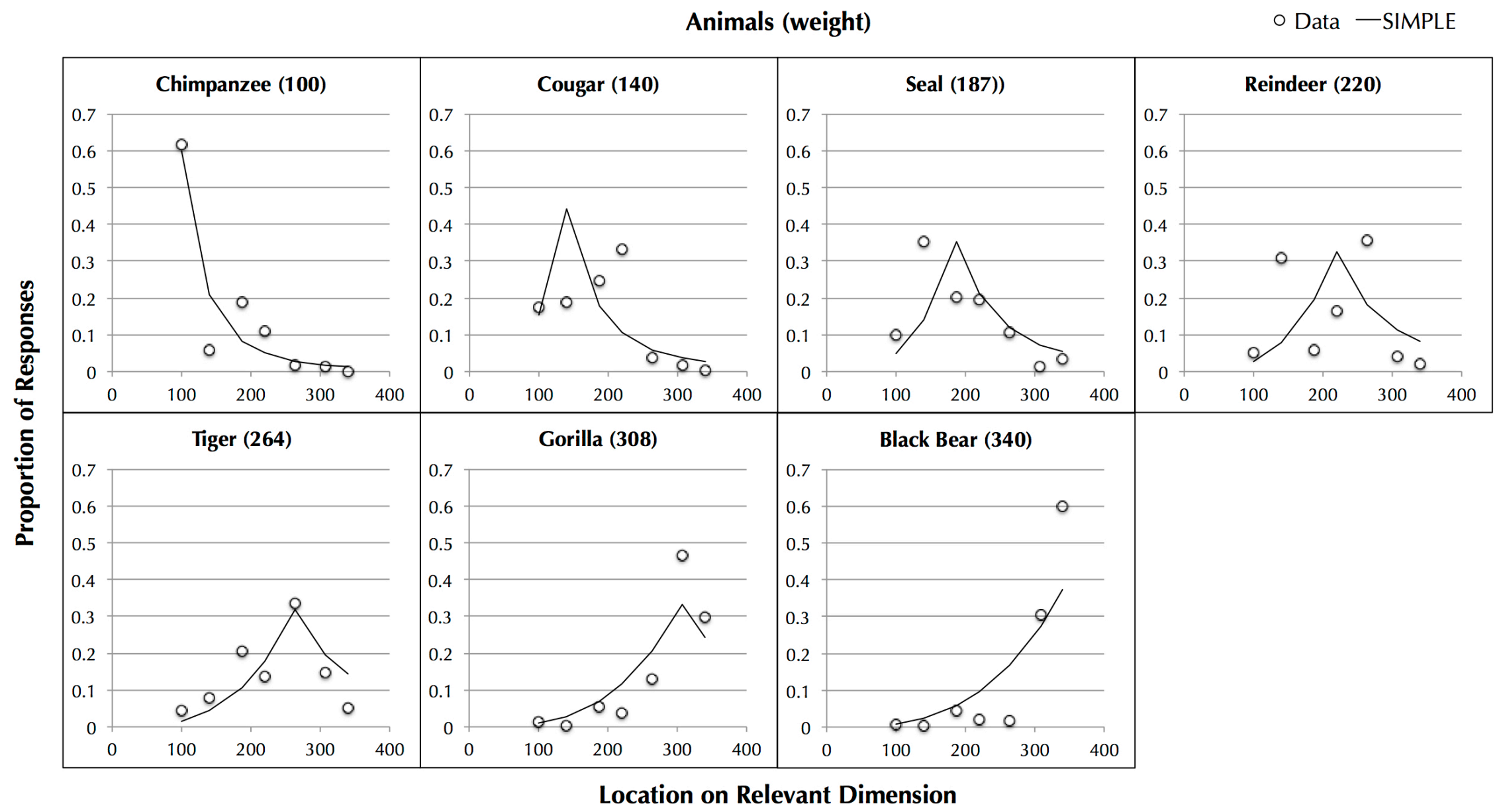


Figure 4 Panel C

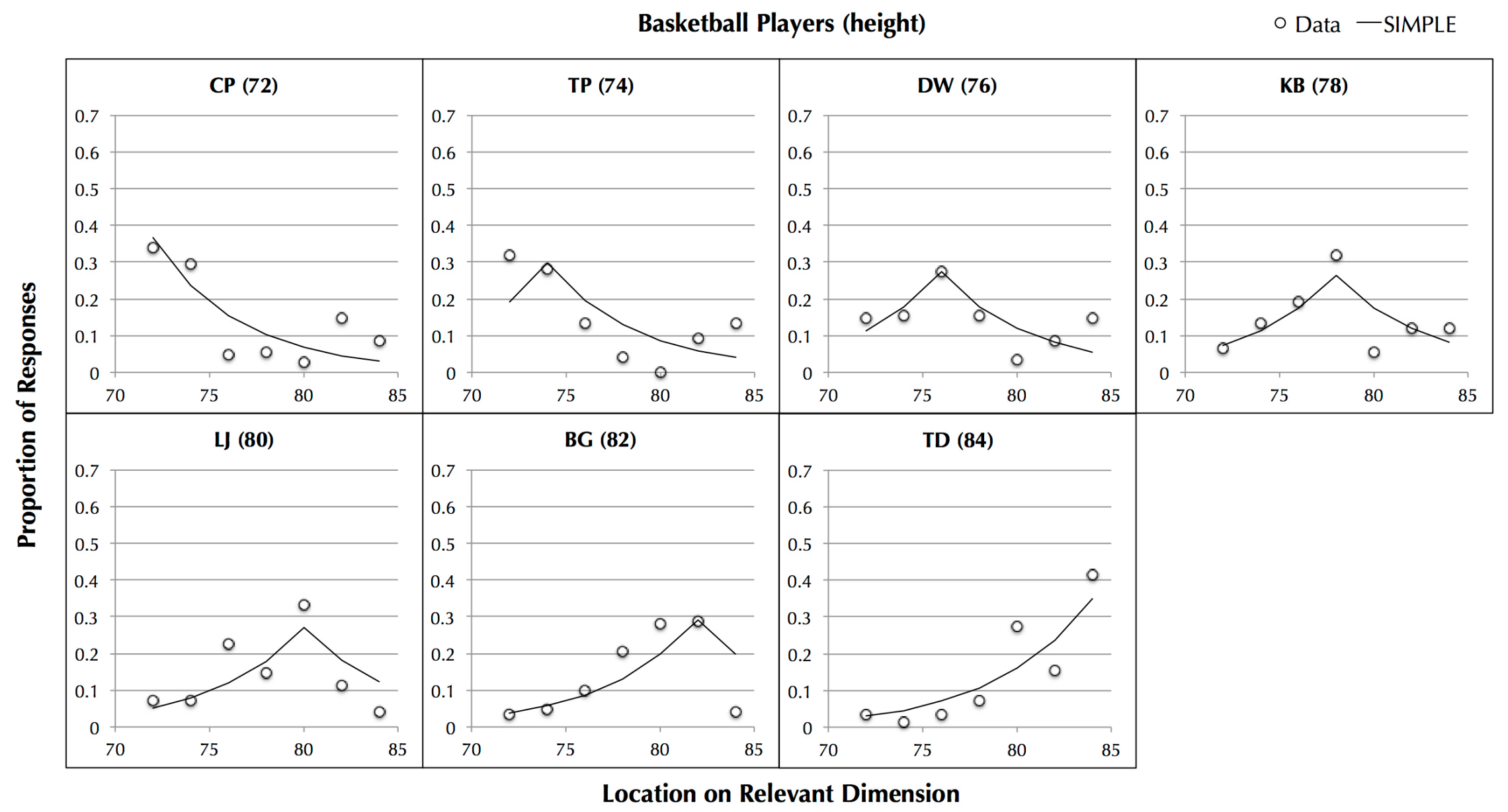


Figure 4 Panel D

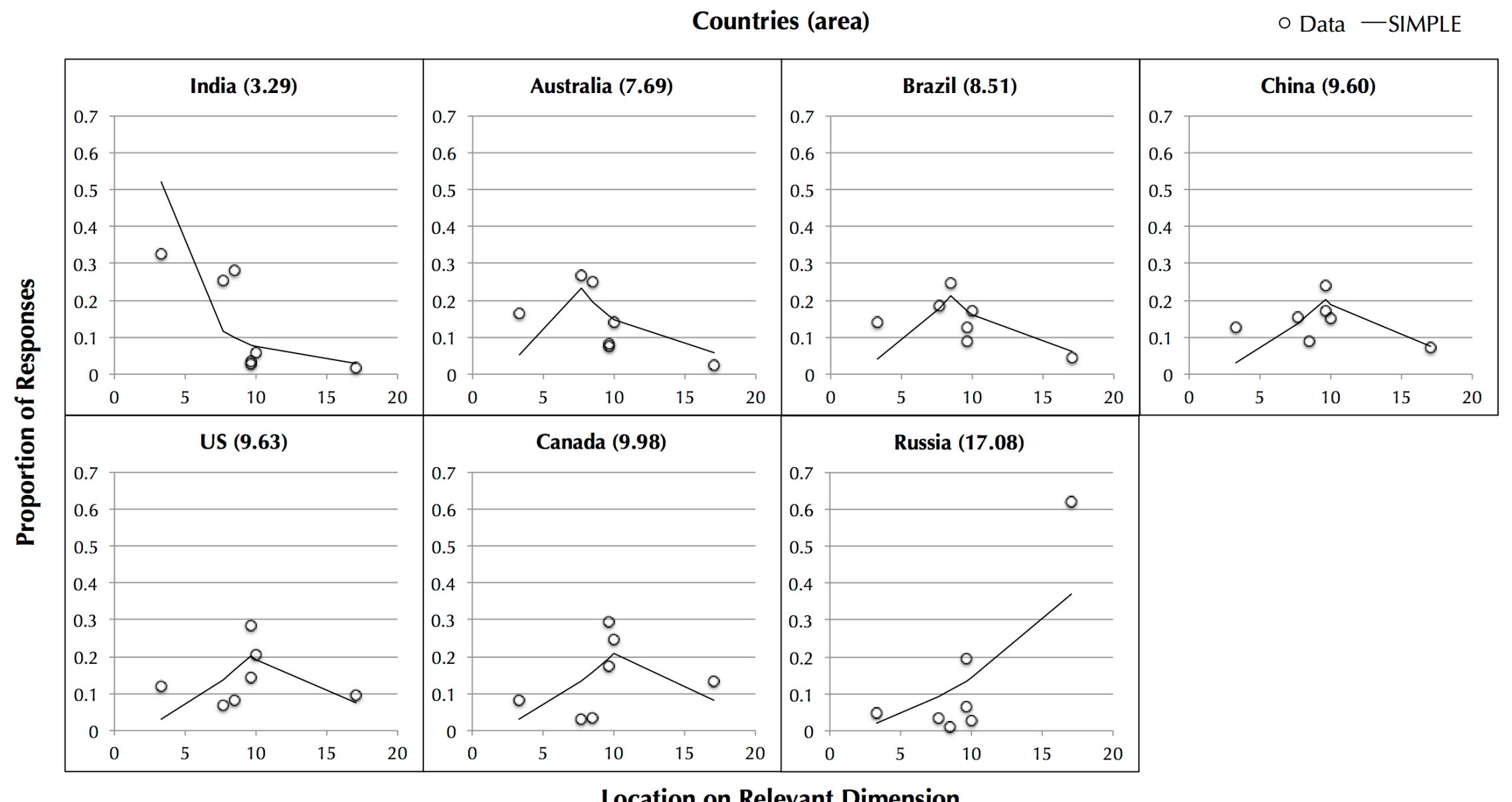


Figure 4 Panel E

Planets (diameter)

- Data - SIMPLE
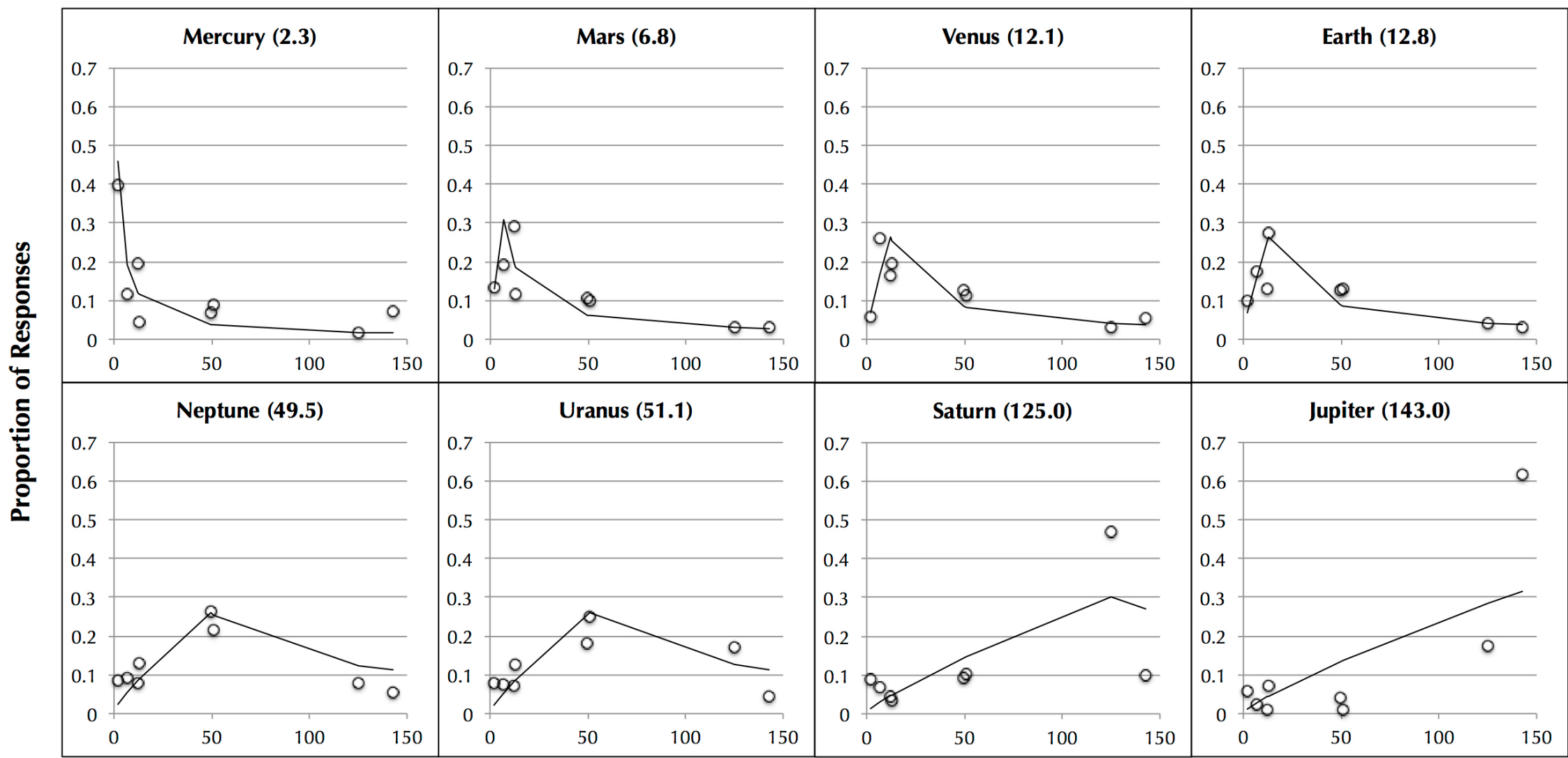

Location on Relevant Dimension 